\title{
Characterization of pancreas in Sudanese Population Using Computerized Tomography
}

\author{
Afraa Siddig Hassan ${ }^{1}$, Caroline Edward Ayad ${ }^{1, *}$, Tag Eldeen Mohammed Ebrahim², \\ Elsafi Ahmed Abdalla ${ }^{1}$ \\ ${ }^{1}$ Sudan University of Science and Technology, College of Medical Radiological Science, Khartoum, Sudan \\ ${ }^{2}$ Modern Medical Centre, Khartoum, Sudan
}

\section{Email address:}

Afraasedig@yahoo.com (A. S. Hassan), carolineayad@yahoo.com (C. E. Ayad), carolineayad@sustech.edu (C. E. Ayad), dr.elsafi@gmail.com (E. A. Abdalla),dr.elsafi@sustech.edu (E. A. Abdalla), tageldeen@yahoo.com (T. M. Ebrahim)

\section{To cite this article:}

Afraa Siddig Hassan, Caroline Edward Ayad, Tag Eldeen Mohammed Ebrahim, Elsafi Ahmed Abdalla. Characterization of Pancreas in Sudanese Population Using Computerized Tomography. International Journal of Medical Imaging. Vol. 2, No. 5, 2014, pp. 119-124. doi: 10.11648/j.ijmi.20140205.15

\begin{abstract}
Normal pancreas has variable sizes therefore this study was conducted to define the normal pancreatic size and CT number for Sudanese to establish a local reference value. A total number of 241 Sudanese subjects were included in the study, 161 (66.8\%) were males and $80(33.2 \%)$ were females, their mean ages were $40.6 \pm 16.1$; all were examined using cross-sectional computerized tomography (CT) imaging for abdomen. The subject's ages and gender were recorded and the body characteristics including height, weight, BMI, abdomen circumference (AC), were evaluated and correlated with pancreas size and CT number. This study revealed that the head of pancreas size was $27.9 \pm 4.5 \mathrm{~mm}$, the body was $23.1 \pm$ $3.7 \mathrm{~mm}$, and tail was $19.0 \pm 3.1 \mathrm{~mm}$, while the CT number (Hounsfield unit) was $59.1 \pm 14,57.3 \pm 12.6$ and $55.2 \pm 13.1$ respectively. Also the study showed a significant relation between the pancreas size, pancreas CT number, age, and AC at $(\mathrm{p}<0.05)$.
\end{abstract}

Keywords: Pancreas Measurement, CT scan, CT Number

\section{Introduction}

Pancreas is a mixed lobulated pinkish grey colored gland lying transversely across the posterior abdominal wall extending from the concavity of duodenum to the hilum of spleen forming the stomach bed [1].Being a mixed gland, the pancreas consists of two distinct populations of cells, the exocrine cells secrete enzymes into the digestive tract, and the endocrines secrete hormones into the blood stream [2]. Studies mentioned that both endocrine and exocrine cells arise from the same endodermal rudiment [3].Knowledge about the normal radiographic anatomy of pancreas is required [4]. Different studies on the morphometry of pancreas were obtained [5,6]. All these studies were obtained from various ethnic groups and different geographical situations. The ethnicity, body weight, genetic makeup and nutritional status affect the size of pancreas [7]

In recent years, pancreatic imaging has improved with the introduction of Ultrasonography (US), Computerized Tomography (CT), Magnetic Resonance Imaging (MRI) and
Positron Emission Tomography (PET) and may provide an advance enhancement in the morphological study of pancreas. [8]Using the cross-sectional imaging, the pancreatic size is commonly expressed by the anterior-posterior (AP) diameters of the tail, body, and head $[9,10]$.

As the morphology differs regarding the race; therefore it is justifiable to carry out a study on the pancreatic morphometry in Sudanese subjects with no history of pancreatic disease or diabetes. To the best of our knowledge, no similar study was done for Sudanese population in the open literature regarding the pancreas, therefore this research was conducted to characterize the pancreas and establish a local reference of values for the pancreas measurements of the Sudanese subjects.

\section{Materials and Methods}

\subsection{Area and Duration}

This study was achieved at Radiology Department 
Ebn-Elhitham Hospital Khartoum-Sudan, during the period from November 2012 to November 2013.

\subsection{Study Sample and Scanning Protocol}

The study included 241 Sudanese subjects who were scanned for abdomen CT .Patients who were diagnosed as normal pancreas and had no history of diabetes or disease affected pancreas were included. Excluding criteria were the presence of CT signs of any pancreatic or peri-pancreatic pathology. Thus, the patients with the acute and chronic pancreatitis or pancreatic neoplasm were excluded .In addition, the patients with various pathological conditions affecting the adjacent organs (stomach, spleen, peritoneum, or retro peritoneum), such as large tumors, fluid collections, massive lymph nodes enlargement with the consecutive compression, infiltration, or displacement of the pancreas, were also excluded. Axial images were obtained using Toshiba 4 slice CT scanner (Asetation AS 2010). Iodinated contrast medium at a dose of $2 \mathrm{mgI} \mathrm{kg}{ }^{-1}$ of body weight was injected. CT scans were obtained with the patient in supine position during full inspiration. The scan range was from the lung base to the lower margin of the iliac crest. The exposure parameters were $120 \mathrm{kVp}$ and $250 \mathrm{~mA}$.

\subsection{Method of Pancreas Measurement}

The measurements were taken from the operator council of the CT machine; the axial images were obtained through the middle of the pancreatic portion (head, body and tail) .Anterior-posterior diameters (AP) were measured at right angles to the longitudinal axis of the organ. The largest diameter of the pancreas lying to the left of the middle of the vertebral body was considered the head. The body of the pancreas was measured on the left margin of the vertebral body and the tail opposite to the medial margin of the left kidney. The transverse diameter of the adjacent vertebral body was measured and used as a reference and marker of body character as applied by Andreas [11]. The CT numbers for the pancreas head, body and tail were measured (Hounsfield). The CT number of the lumber Vertebra was also been evaluated.

\subsection{Method of Statistical Analysis}

All data obtained in the study were documented and analyzed using SPSS version16 for windows (SPSS Inc, Chicago, IL).Descriptive statistics, were presented with mean \pm standard deviation (SD), maximal (Max), and minimal (Min) values. Independent samples t- test was used to estimate the sex-related differences. Pearson's correlation coefficient was used to evaluate the correlations of the size of the pancreas with the subject's age, and parameters of body character. P-value of less than 0.05 was considered to be statistically significant. Linear regression models were performed between the variables which have significant relations and equations were created.

\section{Results and Discussion}

The pancreas is a particularly important organ from the point of view of human medicine because it is subject to two important diseases: Diabetes Mellitus and pancreatic cancer. Despite this medical importance, the developmental natural science of the pancreas has attracted only a small number of researchers in recent years. Lack of awareness invariably devotes studying the exocrine and endocrine pancreas as though; they were entirely separate organs and the lineage of the cell types is far to be understood. Considering the seriousness of pancreatic diseases and the importance of its correct diagnosis and treatment, a morphmetric study of pancreas among Sudanese population has emerged as a demand of present time.

This study was carried out to establish normal dimensions of pancreas especially for Sudanese to be considered as local reference which could be a guideline for the correct diagnosis, treatment and research on various relevant diseases. The following tables presented the data obtained from 241 Sudanese subjects (161 were males and 80 were females). The compared means and standard deviation between genders and the subjects demographic data including age, height, weight, BMI, abdominal circumference were presented in table (1).

This study used the Anterior-posterior (AP) diameters of the head, body, and tail of the pancreas because they are the most widely used measuring diameters for the determination of pancreatic size by the cross-sectional imaging methods. $[12,13]$

Table (1). Compare Means and standard deviation, of (Age, height, weight, BMI, Abdominal Circumference) measured for Sudanese subjects (males and Females)

\begin{tabular}{llllll}
\hline Gender & Age & Height & Weight & BMI & $\begin{array}{l}\text { Abdomen } \\
\text { Circumference }\end{array}$ \\
\hline Male & 39.5 & 168.6 & 71.0 & 25.9 & 87.0 \\
& \pm 6.1 & \pm 22.3 & \pm 19.0 & \pm 5.2 & \pm 20.26 \\
Female & 42.6 & 157.3 & 67.2 & 29.9 & 87.2 \\
& \pm 5.9 & \pm 18.8 & \pm 16.6 & \pm 22.4 & \pm 17.9 \\
$P$-value & 0.161 & $0.000^{*}$ & 0.133 & 0.102 & 0.847 \\
\hline
\end{tabular}

*Normal p-value is 0.05 ; therefore the statistical difference is significant, the data express as Mean $\pm \mathrm{SD}$.

The above table showed that only the height is significantly different with gender, such differences probably resulted from the anthropometric differences between males and females. [14]

Table (2). Mean and standard deviation, Minimum and Maximum values of Pancreases head, body and tail Size measured for Sudanese subjects

\begin{tabular}{llll}
\hline Variable & $\begin{array}{l}\text { Pancreases } \\
\text { Head Size }\end{array}$ & $\begin{array}{l}\text { Pancreases } \\
\text { Body Size }\end{array}$ & $\begin{array}{l}\text { Pancreases } \\
\text { Tail Size }\end{array}$ \\
\hline Mean \pm SD & $27.9 \pm 4.5$ & $23.1 \pm 3.7$ & $19.0 \pm 3.1$ \\
Minimum & 13.1 & 12.6 & 9.7 \\
Maximum & 66.9 & 35.0 & 30.5 \\
\hline
\end{tabular}

In CT imaging, the interpretation of pancreatic pathology rests on the appreciation of the appearance of the normal 
pancreas. The normal anterior-posterior width of the body of the pancreas varies, but $20 \mathrm{~mm}$ is accepted as the upper limit of normal. The normal upper limit for width of the pancreatic head ranges between $25-30 \mathrm{~mm}$, and pancreatic tail is $15 \mathrm{~mm}$. These are at best only a rough guide to pancreatic size, and it is important to correlate the full dimensions of the gland when evaluating the suspected pancreatic enlargement. [15]

AP diameters of the pancreas in our series were different and not compatible with the values reported in the literature $[16,17]$ as noticed in table (2)

Table (3). Compare Means and Correlation between (Pancreas Head size, Pancreas Body size and Pancreas Tail size) with gender

\begin{tabular}{llll}
\hline Variable & $\begin{array}{l}\text { Pancreases } \\
\text { Head Size }\end{array}$ & $\begin{array}{l}\text { Pancreases } \\
\text { Body Size }\end{array}$ & $\begin{array}{l}\text { Pancreases } \\
\text { Tail Size }\end{array}$ \\
\hline Male & $28.0 \pm 3.9$ & $23.3 \pm 3.4$ & $19.1 \pm 3.01$ \\
Female & $27.6 \pm 5.5$ & $22.9 \pm 4.3$ & $18.9 \pm 3.2$ \\
P-value & 0.513 & 0.354 & 0.404 \\
\hline
\end{tabular}

The data were expressed as Mean $\pm \mathrm{STDV},{ }^{*}$ Normal p-value is 0.05

The compared means of pancreas measurements showed that there were no significant differences between the two genders as seen in table (3).However another study showed that the measured diameters of the pancreas were different between the two genders. [15]

Table (4). Correlation between (Pancreases Head, Body and Tail Size)with others variables

\begin{tabular}{llll}
\hline Variables & $\begin{array}{l}\text { Pancreases } \\
\text { Head Size }\end{array}$ & $\begin{array}{l}\text { Pancreases } \\
\text { Body Size }\end{array}$ & $\begin{array}{l}\text { Pancreases } \\
\text { Tail Size }\end{array}$ \\
\hline Age & 0.690 & $0.011^{*}$ & $0.042^{*}$ \\
Gender & 0.058 & 0.576 & 0.252 \\
Height & $0.001^{*}$ & $0.000^{*}$ & $0.000^{*}$ \\
Weight & $0.000^{*}$ & $0.000^{*}$ & $0.000^{*}$ \\
BMI & 0.527 & 0.585 & 0.898 \\
AC & 0.084 & $0.011^{*}$ & $0.004^{*}$ \\
VBTD & $0.024^{*}$ & $0.001^{*}$ & $0.016^{*}$ \\
VBCT & 0.909 & 0.773 & 0.158 \\
\hline
\end{tabular}

* Correlation is significant at $\mathrm{P}=0.05$. BMI=Body Mass Index, $\mathrm{AC}=\mathrm{Abdominal}$ circumference, $\mathrm{VBTD}=$ Vertebral body transverse diameter, $\mathrm{VBCT}=$ vertebral body $\mathrm{CT}$ number.

Correlation between the variables were studied and presented in table (4). Linear regression models were performed between patients demographic data and the pancreas measurements. Equations were created from the significant relations.

Age $=24.07+0.71$ X Pancreas Body Size.

Age $=27.53+0.69$ X Pancreas Tail Size

The Sudanese pancreas body and tail sizes can be predicted when the subjects' ages were known. As the ages increased, the pancreas body sizes were also increased by 0.71 starting from $24.07 \mathrm{~mm}$, and the tail size increased by
$0.69 \mathrm{~mm}$ starting from $27.53 \mathrm{~mm}$. (Eq.1, 2)

The impact of age on pancreas measurements was studied previously [15]. Our study findings were not consigned with these results. Other results had mentioned that parenchymal pancreatic measurements have reached a maximum in the third decade of age, remaining constant until 60 years of age thereafter and it gradually decreases [15]. However the study in Sudanese pancreas size was best described by the established age related formula. The use of the proposed formula, which includes commonly measured diameters of the pancreas by cross-sectional imaging, will provide fast calculation of the approximate pancreatic size in the regular clinical practice. One study had also reported that in adults beyond 60 years of age, both total and parenchymal pancreas measurements gradually decline and fat infiltration of the pancreas have been reported with aging in humans $(16,17)$. Previous anatomical studies reported that pancreas measurements decreased after age 60 (18, 19, 20). Ultrasound studies report increased pancreatic echogenicity with aging, suggesting the age-related fat accumulation in the pancreas $(21,22)$. Others have reported age-related morphological changes of the pancreas by CT imaging (23) Heuck et al. reported the decreased pancreatic measurements and increased lobulation in elderly humans.[23] Our study showed the impact of age on the AP -dimensions of pancreas regardless of the change in each decade separately.

The Sudanese pancreas body and tail sizes can be calculated when the subjects' heights and weights were known. As the heights increased the pancreas head, body and tail sizes were also increased by1.02, 1.39 and $2.03 \mathrm{~mm}$ for head, body and tail, respectively. As the weight increased the pancreas head size increased by 1.3 starting from $33.9 \mathrm{~mm}$, body size increased by 1.84 starting from $27.25 \mathrm{~mm}$, and the tail size increased by 2.24 starting from $27.22 \mathrm{~mm}$.When the Sudanese subjects abdomen circumferences (AC) were known; the pancreas body and tail sizes can also be calculated. As the abdomen circumferences increased; the pancreas body sizes were also increased by 0.87 starting from 67.47 , and the tail size increased by $1.16 \mathrm{~mm}$ starting 65.39 these were noticed in the following equations.

Subjects height $=136.5+1.02 \mathrm{X}$ Pancreases head size.

Subjects height $=132.7+1.39 \mathrm{X}$ Pancreases body size.

Subjects height $=126.3+2.03 \mathrm{X}$ Pancreas tail size.

Subjects weight $=33.9+1.3$ X Pancreas head size.

Subjects weight $=27.25+1.84$ X Pancreas body size.

Subjects weight $=27.22+2.24 \mathrm{X}$ Pancreas tail size. 
Subjects $(\mathrm{AC})=67.47+0.87 \mathrm{X}$ pancreas body size .

Subjects $(\mathrm{AC})=65.39+1.16 \mathrm{X}$ pancreas tail size.

(Eq.10)

The pancreatic sizes for head, body and tail, could be computed employing the above formulae for height, weight and $\mathrm{AC}$.The differences reflect the body habitus of the investigated subjects.These Findings are consistent with the fact that the organ size usually correlates with body height and weight [20] .Our justification pointed that ethnicity and nutritional status may affect the size of pancreas [7].The study showed no significant relationship between the pancreas measurements and BMI .However a study done by Silva et al reported that the diameters of the head, body, and tail of the pancreas measured by ultrasonography had relation with BMI.[21]The transverse diameter of the lumbar vertebral body, which is considered representative of body habitus, was included in the calculations .Similar studies were obtained concerning this consistency. [25] When the Sudanese vertebra body sizes (VBS) are known; the pancreas head, body and tail sizes can be predicted. As the vertebral body size increased; the pancreas head, body, tail sizes were increased by $0.13,0.23$, and $0.20 \mathrm{~mm}$ these were noticed in the following equations.

$(\mathrm{VBS})=34.9+0.13 \mathrm{X}$ pancreas head size .

$(\mathrm{VBS})=33.21+0.23 \mathrm{X}$ pancreas body size.

$(\mathrm{VBS})=34.69+0.20 \mathrm{X}$ pancreases tail size.

No significant relations were detected between vertebra body CT number and the pancreas measurements. The importance of the knowledge about the pancreas normal size; is that the pancreas size is very important in the evaluation of protein energy malnutrition patients, and these measures could also be used as a predictive parameter [26] and any changes in size may affect its function. As researchers had explained that the pancreatic size reduction in type 1 and 2 diabetes may be secondary to a reduced insulinotropic effect on the acinar cells [27], therefore, it can be explained that the reduction of endocrine cells which constitute only two percent of the pancreas can lead to reduction of the exocrine glandular tissue as well [27]. This also reflects the importance to know the normal size of the pancreas in order to be able to predict any changes that may occur.

Table (5). Mean and standard deviation, Minimum and Maximum values of (Pancreases Head, Body and Tail (CT number) measured for Sudanese Subjects

\begin{tabular}{llcl}
\hline Variable & $\begin{array}{c}\text { Pancreases } \\
\text { Head CT } \\
\text { number }\end{array}$ & $\begin{array}{c}\text { Pancreases Body } \\
\text { CT number }\end{array}$ & $\begin{array}{c}\text { Pancreases Tail } \\
\text { CT number }\end{array}$ \\
\hline Mean \pm SD & $59.1 \pm 14.1$ & $57.3 \pm 12.6$ & $55.2 \pm 13.1$ \\
Minimum & 27.7 & 13.0 & 10.0 \\
Maximum & 137.0 & 115.0 & 101.0 \\
\hline
\end{tabular}

Table (6). Compare Means and Correlation between (Pancreas Head, Body and Tail CT number with gender

\begin{tabular}{lccc}
\hline Variable & $\begin{array}{c}\text { Pancreases Head } \\
\text { CT number }\end{array}$ & $\begin{array}{c}\text { Pancreases } \\
\text { Body CT } \\
\text { number }\end{array}$ & $\begin{array}{c}\text { Pancreases } \\
\text { Tail CT } \\
\text { number }\end{array}$ \\
\hline Male & $57.4 \pm 11.8$ & $56.1 \pm 10.3$ & $54.0 \pm 12.3$ \\
Female & $62.5 \pm 17.5$ & $59.7 \pm 16.2$ & $57.5 \pm 14.5$ \\
P-value & $0.009^{*}$ & $0.037^{*}$ & $0.047^{*}$ \\
\hline
\end{tabular}

The data were expressed as Mean $\pm \mathrm{STDV}$, *Normal p-value is 0.05 .

Table (7). Correlation between (Pancreases Head, Body and Tail CT number) with others variables

\begin{tabular}{lccc}
\hline Variables & $\begin{array}{c}\text { Pancreases } \\
\text { Head CT } \\
\text { number }\end{array}$ & $\begin{array}{c}\text { Pancreases } \\
\text { Body CT } \\
\text { number }\end{array}$ & $\begin{array}{c}\text { Pancreases } \\
\text { Tail CT } \\
\text { number }\end{array}$ \\
\hline Age & $0.020^{*}$ & $0.000^{*}$ & $0.000^{*}$ \\
Gender & $0.029^{*}$ & 0.073 & 0.166 \\
Height & 0.643 & 0.758 & 0.902 \\
Weight & 0.122 & $0.019^{*}$ & $0.019^{*}$ \\
BMI & 0.804 & 0.381 & 0.312 \\
AC & 0.175 & $0.009^{*}$ & $0.019^{*}$ \\
VBTD & $0.021^{*}$ & 0.063 & $0.032^{*}$ \\
VBCT & 0.274 & 0.112 & $0.002^{*}$ \\
\hline
\end{tabular}

*Correlation is significant at $\mathrm{p}=0.05$. BMI=Body Mass Index, $\mathrm{AC}=\mathrm{Abdominal}$ circumference, $\mathrm{VBS}=$ Vertebral body transverse diameter, $\mathrm{VBCT}=$ vertebral body $\mathrm{CT}$ number

Table (5) presented the mean and standard deviation, minimum and maximum values of pancreases head, body and tail (CT number) measured for Sudanese subjects. The study revealed that there were significant difference between the pancreas CT numbe and the two genders as presented in table (6)

Correlation between pancreases head, body and tail CT number with other variables were evaluated and presented in table (7).The pancreas CT number had significant relation with age at $p$-value $=0.000$. The justification to have relation with age could be due to decline in the glandular tissue as well as the fatty connective tissue within the substance of the gland in elderly people [28]. The correlation between the pancreas CT number and the variables was studied, and regarding the significant relations; predictive equations that defined body habitus were established; these equations provided predictive ability for important physical measures that defined pancreas size.(Eq 14-16)

Age $=50.65-0.17 \mathrm{X}$ Pancreas head CT number.

Age $=61.86-0.37 \mathrm{X}$ Pancreas body CT number.

Age $=62.30-0.39 \mathrm{X}$ Pancreas tail CT number.

Sudanese pancreas, head, body and tail CT number can be measured when the subjects' ages were known. As the ages increased the pancreas head, body and tail CT number decreased by $0.17,0.37$ and 0.39 , respectively. This reduction can be due to the fact that the structural and functional properties differ significantly in the exocrine and 
endocrine pancreas and age. [29] A number of structural changes have been described in the aging pancreas. Results from earlier literature reported that the organ decreases in weight after the seventh decade of life in humans, and it becomes harder $[30,31,32]$ in addition, histological changes such as ductal epithelial hyperplasia, intralobular fibrosis, and acinar cell de-granulation have been described. These morphologic changes in the aging pancreas have been attributed to pancreatic involution leading to decreased secretory capacity of the exocrine pancreas $[31,33]$

Weight=82.25-0.22 X Pancreas body CT number.

(Eq.17)

Weight $=81.43-0.21 \mathrm{X}$ Pancreas tail CT number.

$(\mathrm{AC})=102.22-0.26 \mathrm{X}$ Pancreas body CT number.

$(\mathrm{AC})=99.89-0.23 \mathrm{X}$ Pancreas tail CT number.

The above equations presented that the pancreas body and tail CT number, were reduced as the subjects weight and abdominal circumference increased.

For the reference value as vertebra body transverse diameter (VBTD) and CT number (VBCT); the following equations were also established:

$\mathrm{VBTD}=41.02-0.04 \mathrm{X}$ pancreas head CT number. $\quad($ Eq.21)

$\mathrm{VBTD}=34.7+0.20 \mathrm{X}$ pancreas tail CT number. $\quad($ Eq.22)

VBCT $=210.37-0.76 X$ Pancreas tail CT number. $\quad$ (Eq.23)

A negative linear relationship was found between the pancreas head CT number and VBTD; it reduced by 0.04 starting from 41.02 .The pancreas tail CT number had positive linear relation with VBTD and negative relation with VBCT. The differences in CT number of the pancreas head, body and tail in the CT images, were justified to be due to pancreas differentiation of cells, its proceeding through two different pathways, corresponding to the dual endocrine and exocrine functions of the pancreas [34].

In progenitor cells of the exocrine pancreas, important molecules that induce differentiation; include follistatin, fibroblast growth factors, and activation of the notch receptor system [29].

Development of the exocrine acini progresses include the pre-differentiated, proto-differentiated, and differentiated stages, which correspond to undetectable, low, and high levels of digestive enzyme activity, respectively. That means the difference in structure and function might cause those differences in CT number readings for the pancreas head, body and tail, as the pancreas is being a mixed gland.

\section{Conclusion}

The study concluded that axial CT scan is considered as an appreciable radiological method for measuring the pancreas size and characterizing its structure using CT number (Hounsfield). The study also revealed that the Sudanese pancreas is different from what was mentioned in the literature and other previous studies, and also pancreas size and CT number had significant relations with age and other body habitus. Sudanese pancreas size and CT number were best described by the established formulae for age, weight, height, AC, VBTD, VDCT. Local references for Sudanese pancreas measurements and CT number were established.

\section{Acknowledgements}

We sincerely thank the participants without whom the study would not have been feasible. The Sudan University of Science and Technology, College of Medical Radiological Science and Radiology Department -Ebn-Elhitham Hospital Khartoum-Sudan are thankfully acknowledged.

\section{References}

[1] Williams PL, Warwick R, Dyson M, Bannister HL. The Pancreas. Gray's Anatomy. 37th Ed. Edinburg Churchill Livingstone. 1989; 1140-53.

[2] McMinn RMH, Rose PG, Hutchings RT, Logan BM. (1995).Pancreas. McMinn's Functional and Clinical Anatomy Mosby; 277-9.

[3] Slack JM. (1995).Developmental biology of the pancreas.Development; 121: $15,69-80$

[4] Vesterhus M, Haldorsen IS, Ræder H, Molven A, Njølstad

[5] PR. (2008) Reduced Pancreatic Volume in Hepatocyte Nuclear Factor1A-Maturity-Onset Diabetes of the Young. J Clin EndocrinolMetabol; 93: 3505-9

[6] Innes JT, Carey LC. (1994)Normal pancreatic dimensions in the adult human Amer J Surg;167:261-300

[7] Romanes GJ. Cunningham's Textbook of Anatomy. 12th Ed.

[8] Oxford University Press. Oxford New York Toronto.1981; 485-8

[9] KS Basnet, TP Thapa, RP Upreti, PMS Dangol, RN Shrestha and S Dhungel .(2011).A morphometric study of human pancreas in Nepalese people Nepal Med Coll J; 13(2): 88-91

[10] Balthazar EJ, Megibow AJ, Pozzi Mucelli R (2009) Imaging ofthe pancreas. Acute and chronic pancreatitis. Springer, Berlin

[11] Wegener OH (1993) Whole body tomography. Blackwell ScientificPublications, Boston, pp 291-293

[12] Andreas Heuck,peter A.Maubach,Maximilian Reisar,Stafan Feuerbach,Berhard Allgayer,Peter Lukas,andThomas Kahn.Age related morphology of the normal pancreas on Computed Tomography, Gastrointest Radiol12:18-22

[13] Acar M, Degirmenci B, Tatli S (2010) Short pancreas: evaluationwith multi-detector row CT. Surg Radiol Anat 32:853-858 
[14] Von Schulz HG, Christou A, Gursky S, Rother P (1986)Computer-tomographic studies on the normal morphology andvolumetry of parenchymatous epigastric organs of man. AnatAnz 162:1-12

[15] A. Djuric-Stefanovic, D. Masulovic,J. Kostic, K. Randjic \& D. Saranovic (2012). CT volumetry of normal pancreas: correlation with the pancreatic diameters measurable by the cross-sectional imaging, and relationship with the gender, age, and body constitution Surg Radiol Anat 34:811-817

[16] Kreel L, Haertel M, Katz D (1977) .Computed tomography of the normal pancreas. J Comput Assist Tomogr. Jul;1(3):290-9.

[17] Noronha M, Salgadinho A, Ferreira De Almeida MJ, Dreiling DA, BordaloO. (1981). Alcohol and the pancreas. I. Clinical associations and histopathology of minimal pancreatic inflammation. Am JGastroenterol 76:114-119.

[18] Stirling GA. (1994). The exocrine pancreas: Non-neoplasmic disorders.In: Wight DGD, editor. Liver, Biliary Tract and Exocrine Pancreas.3rd Ed. New York, NY: Churchill Livingstone. p 597-650.

[19] Rossle R. (1921). [Beitrage zur Kenntnis der gesunden und krankenBauchspeicheldruse]. Beitr Pathol Anat Allg Pathol 69:163-184

[20] Tanaka G, Nakahara Y, Nakazima Y. (1989). [Japanese referenceman 1988-IV. Studies on the weight and size of internal organsof normal Japanese]. Nippon Igaku Hoshasen Gakkai Zasshi49:344-364.

[21] Ogiu N, Nakamura Y, Ijiri I, Hiraiwa K, Ogiu T. 1997. A statisticalanalysis of the internal organ weights of normal Japanese people.Health Phys 72:368-383

[22] Worthen NJ, Beabeau D. (1982). Normal pancreatic echogenicity:Relation to age and body fat. AJR Am J Roentgenol 139:1095-1098

[23] Glaser J, Stienecker K. (2000). Pancreas and aging: A study usingultrasonography. Gerontology 46:93-96

[24] Heuck A, Maubach PA, Reiser M, Feuerbach S, Allgayer B, Lukas P,Kahn T. (1987). Age-related morphology of the normal pancreas on computed tomography. Gastrointest Radiol 12:18-22.
[25] Silva ME, Vezozzo DP, Ursich MJ, Rocha DM, Cerri GG, WajchenbergBL. (1993). Ultrasonographic abnormalities of the pancreas inIDDM and NIDDM patients. Diabet Care6:1296-1297

[26] Geraghty EM, Boone JM (2003) Determination of height, weight,body mass index, and body surface area with a single abdominal CT image. Radiology 228:857-863

[27] El-Hodhod MA, Nassar MF, Hetta OA, Gomaa SM. (2005)Pancreatic size in protein energy malnutrition: a predictor of nutritional recovery. European J Clin Nutr;59: $467-73$.

[28] Vesterhus M, Haldorsen IS, Ræder H, Molven A, NjølstadPR (2008)Reduced Pancreatic Volume in Hepatocyte Nuclear Factor1A-Maturity-Onset Diabetes of the Young. J Clin Endocrinol Metabol; 93: 3505-9

[29] Standring S. Pancreas. Grays Anatomy. The Anatomical Basis, of Clinical Practice 39th Ed. Churchill Livingstone. Edinburg,London New York 2005; 1231-7

[30] Adhip P. N. Majumdar, Richard Jaszewski and Michael A. Dubick,(1997) Effect of Aging on the Gastrointestinal Tract and the Pancreas Exp Biol Med (Maywood) 215: 134

[31] Andrew W. Senile (1944)changes in the pancreas of Wistar Institute rats and of man with special regard to the similarity of locale and cavity formation. Am J Anat 74:97-127,

[32] Laugier R, Bernard J-P, Berthezene P, Dupuy P.(1991)Changes in pancreatic exocrine secretion with age: Pancreatic exocrine secretion does decrease in the elderly. Digestion 50:202-211,

[33] Geokas MC, Conteas CN, Majumdar PN. (1985)The aging gastrointestinal tract, liver, and pancreas. Clin Geriatr Med $1: 177-205$

[34] Vellas B, Balas D, Moreau J, Bouisson M, Senegas-Balas F, Guidet M, Ribet A. (1988)Exocrine pancreatic secretion in the elderly. Int J Pancreatol 3:497-502

[35] Carlson, Bruce M. (2004). Human embryology and developmental biology. St. Louis: Mosby. pp. 372-4. ISBN $0-323-01487-9$ 